\title{
Simulation and Formation Mechanisms of Urban Landscape Design Based on Discrete Dynamic Models Driven by Big Data
}

\author{
Ke Cao $\left(\mathbb{D},{ }^{1}\right.$ Jing Xiao $\mathbb{D}^{2},{ }^{2}$ and Yan $\mathrm{Wu} \mathbb{D}^{3}$ \\ ${ }^{1}$ School of Management, Chongqing Technology and Business University, Chongqing 400067, China \\ ${ }^{2}$ School of Architecture and Urban Planning, Chongqing University, Chongqing 400045, China \\ ${ }^{3}$ School of Architecture, Zhengzhou University, Zhengzhou 450001, Henan, China \\ Correspondence should be addressed to Ke Cao; caoke@ctbu.edu.cn
}

Received 16 November 2021; Revised 14 December 2021; Accepted 20 December 2021; Published 10 January 2022

Academic Editor: Gengxin Sun

Copyright (c) $2022 \mathrm{Ke}$ Cao et al. This is an open access article distributed under the Creative Commons Attribution License, which permits unrestricted use, distribution, and reproduction in any medium, provided the original work is properly cited.

\begin{abstract}
Urban landscape design as a contemporary art embodies postmodernist philosophical thinking, aesthetic thinking, and breaking the traditional concept of art, and it is a new way of creating and presenting art. Big data technology characterized by large scale, speed, variety, value, and uncertainty of data is used to achieve urban landscape design. In this article, during the research process, we strive to raise the revelation of the design layer rather than the brand new level of cross-fertilization and interaction between big data-driven discrete dynamic model and urban landscape design; we also reveal how the benefits of promoting urban development and harmonious life are achieved in the interactive expression of the urban landscape after the application of the big data-driven discrete dynamic model, which provides designers and related professionals with more detailed and novel design ideas at the theoretical level and makes the theory of big data-driven discrete dynamic models in landscape design interactive methods more enriched. Finally, this article puts forward its thinking and outlook on the design of the big data-driven discrete dynamic model in the interactivity of urban landscape design, hoping that artists will strengthen its functional and material design elements when creating performance. Moreover, more design means of emerging technologies of modern science and technology should be integrated so that modern urban landscape can achieve ordinary and uncommon benefits and promote the rapid development of the big data-driven discrete dynamic model in urban landscape design development.
\end{abstract}

\section{Introduction}

Historically, urban landscape design has been closely linked to the arts, interacting with each other. While today's landscape design has involved many scientific disciplines, it is still heavily influenced by the ever-changing field of art. The profound, subtle, and inner beauty of traditional gardens or the simplicity, ecology [1], and realism of modern gardens all are closely related to the various styles of art, and even when the art world undergoes a radical change, the landscape design world will be influenced by the corresponding changes. When a large number of surrealist paintings emerged in the century, it had a significant impact on designers, including landscape designers who combined the formal language of cubism and surrealism in the art to apply simple and flowing planes in landscape design, beginning to show a dynamic and balanced form. These artistic trends and forms have provided landscape designers with a formal language and creative inspiration [2].

In today's urban development, big data-driven discrete dynamic models are gaining unprecedented momentum in landscape design. More and more designers and artists are focusing on using big data-driven discrete dynamic models and urban landscape design, making the once neglected and aging urban landscape environment fresh and trendy. In the urban public space, the big data-driven discrete dynamic model is influenced by today's new design trend, which tends to be more and more novel, new, and humanized [3], forming a kind of public art interactive communication with urban residents and strengthening the close relationship between the big data-driven discrete dynamic model and the urban landscape environment and public life in a holistic and independent public space, in terms of visual and auditory senses. Truly reflecting the aesthetic value and social 
value of big data-driven discrete dynamic models and letting big data-driven discrete dynamic models enter the life of the public with a more even and free attitude [4] are great problems faced when constructing big data-driven discrete dynamic models today and, however, they are also realistic objectives for contemporary big data-driven discrete dynamic models to obtain higher development goals and realize themselves. The trend of mutual influence and integration between big data-driven discrete dynamic models and the urban landscape is becoming more and more obvious [5].

The design of urban spaces influences our lifestyles, which in turn has an impact on our health. Not all lifestyles are shaped by urban space design; however, the lack of physical exercise, dependence on motorized travel, and sedentary lifestyles are inextricably linked to urban space design. Urban space plays an important role in the pathogenic mechanisms of certain diseases. The landscape environment, as a large component of urban space, plays an important role in creating a healthy environment and inducing positive behaviors and is closely linked to public health issues. A healthy city includes not only a clean, hygienic, natural, and harmonious living environment but also a good and positive social atmosphere. A natural and harmonious living environment is the basis for a healthy and positive social climate, which in turn ensures the sustainability of a natural and harmonious living environment. As an important part of urban public space, urban landscape plays a decisive role in the living environment and social atmosphere to a large extent, whether it is the creation of space or the construction of service facilities. Contemporary medical research confirms that a beautiful environment can play a good role in regulating and promoting the human cerebral cortex and the state of mind and body. Only by creating an environment conducive to promoting healthy behavior can public health be thoroughly improved.

\section{Related Work}

The population expansion, landscape congestion, soaring housing prices, and environmental pollution in large cities are not conducive to developing enterprises and talents, and many domestic high-tech enterprises have chosen to move away from first-tier cities, while the countryside is facing a large loss of land, abandoned residential land [6], large-scale population transfer, and many other problems, and the "big city disease" and "countryside disease" caused by high-speed urbanization are increasingly aggravated. Along with the rapid development of information and communication technology, the development of urban big data has brought great changes to the field of urban planning [7], and the new urban spatial data can, to a certain extent, make up for the shortage of traditional data. Previous population density studies mainly belong to macro analysis and can reduce the research scale to the township road level in the environment of new data, promoting the expansion of research scope and accuracy and helping discover new problems. Exploring how to effectively integrate the traditional Depthmap-based spatial syntax analysis techniques with the big data mining that has emerged in recent years to enhance the explanatory power of complex urban spatial problems, this research direction will become one of the frontier branches of research in the field of urban planning. Therefore, in [8], the combined application research of spatial syntax and big data provides new possibilities for the spatial morphology research of the characteristic town to better solve the construction problems of the characteristic town [9].

In terms of planning, urban morphology is defined as "the spatial and territorial distribution of the city as a whole and its internal components," i.e., urban morphology is a reflection of the spatial structure of the city by various materials [10] and economic and social components in the urban space, expressed in the form of the combination of the elements in the plane or three-dimensional space morphology. Kevin Lynch believed that urban morphology is the orderly arrangement and overall organization of urban environmental elements (roads, boundaries, areas, nodes, and markers) so that the presentation of the overall shape of the city can cause more impact on the visual excitement of the observer [11]. Urban spatial morphology is the characteristic of urban spatial structure and development law, while Mr. Qikang believed that urban morphology is the result of spatial morphological characteristics of the city in the development and change due to internal and external conflicts [12].

The literature has found in experiments that the natural environment can influence and even change the human mood, and the role of landscape in restoring physical and mental health has been demonstrated through a postuse evaluation of rehabilitation gardens, which concluded that natural landscape elements play a major role in promoting the process of restoring health. Guiding principles for rehabilitation landscape design are also presented. The literature is referred to as the founder of the modern hypothesis of rehabilitation gardens and related theories, followed by an experiment on the impact of the external hospital environment on the effectiveness of rehabilitation treatment for patients. After testing, the researchers found that the natural environment has a catalytic effect on easing blood pressure, skin conductivity, and muscle conductivity and that the natural environment enables people to recover more quickly from stressful mental states. Moreover, based on the results of the study, the natural benefit hypothesis is proposed in terms of the health benefits of landscape elements in the natural environment, including water and plants on the human body [13]. By conducting a project practice survey of landscape types under the concept of rehabilitation landscape, the literature argues that rehabilitation landscape provides opportunities for patients to actively recover their functions. It is also the first time to link rehabilitation landscape and urban public space, and it is argued that expanding the scope of rehabilitation landscape and considering the use of rehabilitation landscape in combination with urban public space can effectively promote the physical and mental health of urban residents. The literature argues that both natural and artificial landscape environments have a role in promoting the recovery of human physical and mental health and defines healing landscapes: places, 
facilities, buildings, places [14], and surroundings that are beneficial to the recovery and maintenance of physical and mental health and happiness [15].

\section{Simulation and Formation Mechanisms for Urban Landscape Design Based on Discrete Dynamic Models Driven by Big Data}

\subsection{Big Data-Driven Discrete Dynamic Models. Big data} refers to a collection of datasets that are so large and complex that storage and data processing is difficult using existing general databases. Such datasets were once called "big data," and real-time urban landscape design is an important basis for responding to signal control effects and is a core indicator for calculating or optimizing control volumes, so modeling landscape flows is an essential step [16]. In the landscape engineering community, to study the mechanism of landscape flow and the characteristics of the landscape flow on a macro and micro level, some researchers have established a mathematical model of landscape flow changes through the conservation of urban landscape quantity and the spreading mechanism of landscape quantity; these models have better results in the prediction of local landscape flow. Prelandscape planning analysis is the starting point for carrying out landscape planning work and is the basis for planning and design. Common landscape data include natural information such as site topography, terrain, vegetation, water bodies, soil, meteorology, and human and social information such as population, transportation, economy, and culture. Traditional landscape data mainly exists in the form of paper and pictures [17], such as topographic maps, planning drawings, textual information, hand drawings, and site photos. By mining and analyzing big data, it is possible to quantify text, quantify speech [18], quantify location information, and quantify everything. So far, big data has greatly expanded the information for preanalysis, provided data support for landscape planning, and improved the science of planning and design. The conceptual diagram of the discrete dynamic model is shown in Figure 1.

The discrete industry is characterized by the construction of manufacturing units, which are characterized by high variety, small batch sizes, flexible process routes, and equipment use. In industrial production, companies pay more attention to the flexibility of production, so for the optimization of process control, they pay more attention to the high degree of automation of the manufacturing material flow process, the interconnection and pervasive awareness of all elements involved in the manufacturing process within the factory, and the modeling and simulation of the information-thing system of the manufacturing process. Since its introduction, the discrete choice model has been widely used in various fields, such as marketing, economics, and transportation, to study individual choice behavior. For example, when customers buy a mobile phone, they usually consider its CPU, pixel, resolution, and other attributes before choosing to buy it, and all these mobile phone attributes are not continuous variables but discrete variables, which is difficult to handle using the traditional linear regression model, and it is necessary to use discrete choice model for modeling and analysis [19].

A big data-driven discrete dynamic model is feedback, a system consisting of nonlinear components, where each neuron is connected to all other neurons, classified as discrete (DHNN) or continuous depending on whether the output of the network is discrete or continuous quantity. For the discrete type (DHNN), if the system is stable, it can converge from any state to a stable state; if the system is unstable, since the output of the network nodes only has two states, 1 and -1 (or 1 and 0 ), the system cannot have infinite divergence but only self-sustaining oscillations or limit loops of limited amplitude, finally converging to a stable state adjacent to it. When the evaluation index of the college students to be classified is input, DHNN gradually converges to a stored equilibrium point using its associative memory, and when the state no longer changes [20], the equilibrium point corresponds to the classification level to be sought. The discrete model building process is shown in Figure 2.

Random utility theory is the most basic principle of the discrete choice model: assume that the decision-maker has $n$ options, each of which corresponds to a utility of $U_{i j}$. The utility is defined as a measure of the satisfaction of the consumer's needs and desires through consumption or enjoyment of leisure and $U_{i j}$ is composed of a fixed utility $v$ and a random utility $i j$, with the fixed utility $V_{i j}$ being explained by $i j$ explained by the observable part of factor $x$, while the random utility is the unobservable part, the unpredictable, random variable utility, and error. The decisionmaker chooses the alternative with the maximum utility, which is also called the utility maximization criterion, i.e., satisfaction maximization, and utility $U$ can be expressed as a function of factor $x$ of the observable part of the fixed utility $v$; that is, ${ }_{i j} U_{i j}=x$ is the coefficient. The probability of choosing each alternative can be expressed as a function of utility: $P=F(U)$. The multinomial logit model, the MNL model, is the simplest and most basic form of the discrete choice model, which sets the random utility to obey an independent extreme value distribution so that the choice probability function can be expressed as follows:

$$
M i j=\frac{e^{i j}}{\sum_{i=1}^{n} e_{i}} .
$$

This formula is the core formula of this article. It represents what algorithm the discrete model uses, its applications, and how it applies to the following formulas. The MNL model is easy to operate and quick to use, so the model is popular among scholars and is used in many fields. For example, in landscape design and travel, the model can be used to plan various optimal routes according to people's habits and destinations to provide a reference; in education, the model can be used in teaching practice; in marketing, the model is used in various aspects such as Internet positioning, pharmaceutical pricing, and the selection of electronic products.

The traditional sliding mode variable structure control study object is a continuous system model, while the currently used computer systems are all discrete. When the sliding mode variable structure control is applied to the discrete control 


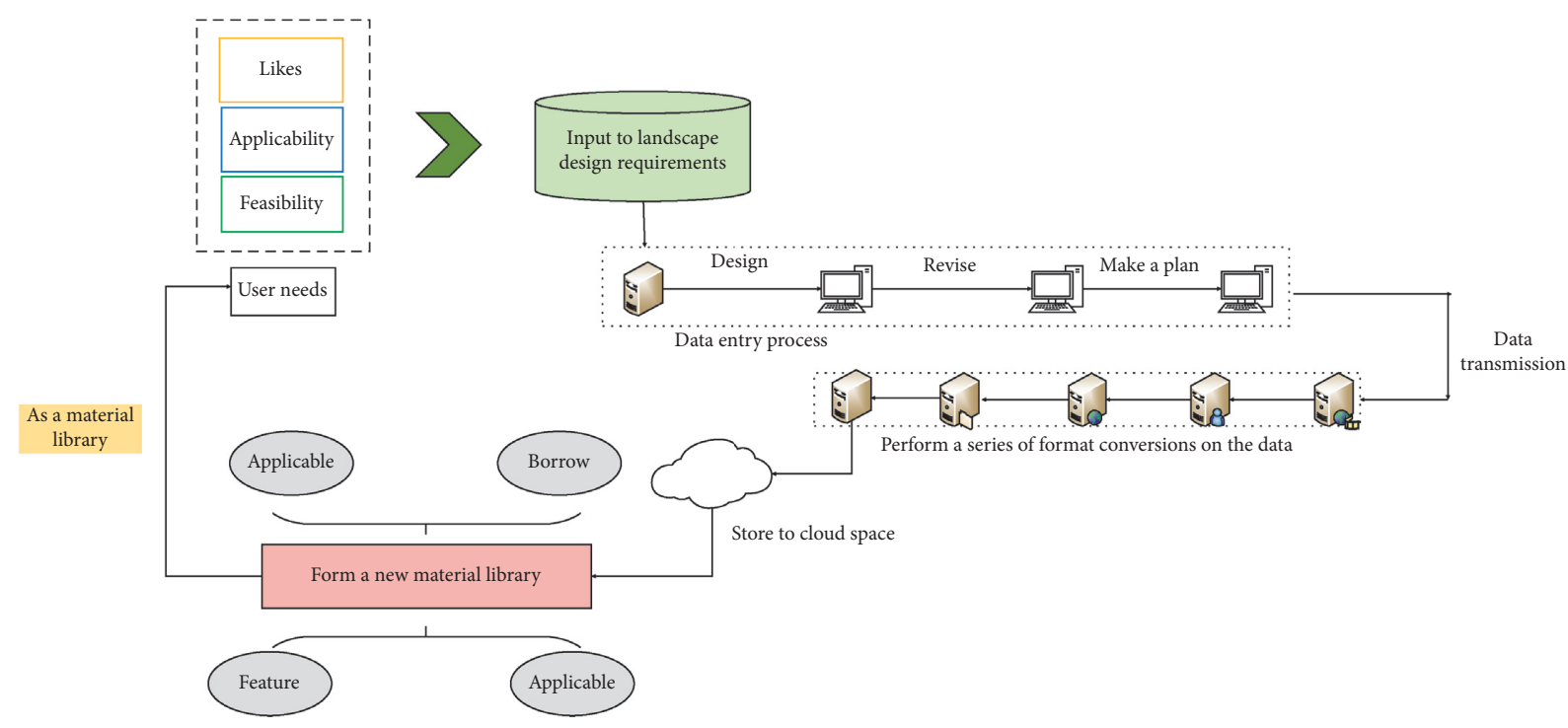

FIgURE 1: Conceptual illustration of the discrete dynamic model.

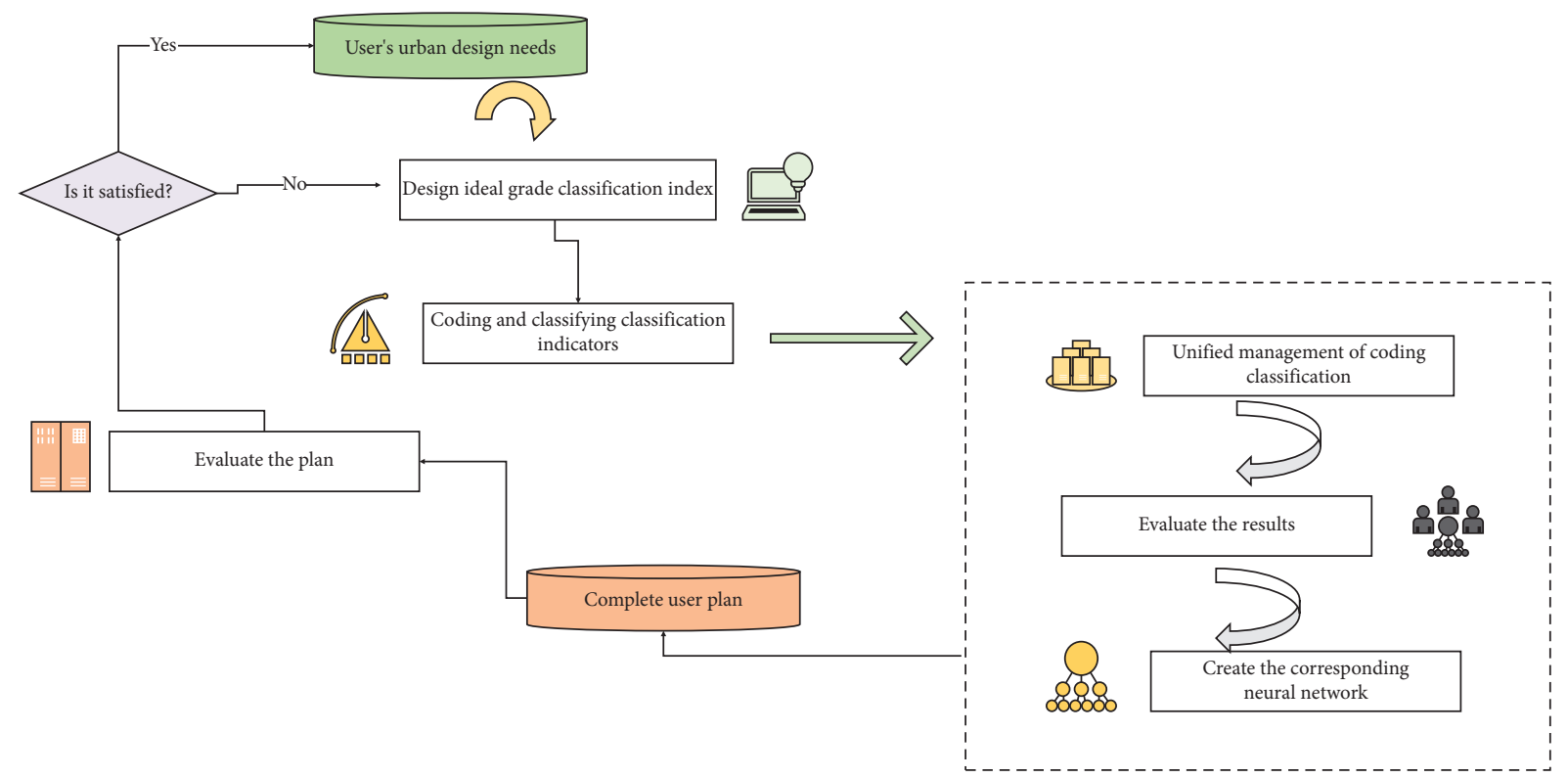

FIgURE 2: Flowchart of discrete model building.

system, due to the influence of sampling frequency, the sliding mode variable structure control can no longer produce the ideal sliding mode. However, the quasisliding mode and motion trajectory can only end up in the form of a jitter along the sliding surface. At present, the research and design of discrete sliding mode variable structure control have become an important part of sliding mode variable structure control theory. The definition of discrete structural control is systematically described as follows:

$$
N i j=\frac{1}{n} \sum_{i=1}^{n}\left(X_{i}-\bar{X}\right)^{2}+\frac{\delta y}{\delta x} .
$$

The existence and arrival conditions of the discrete structure, the existence of which is the basis of the sliding mode motion, are given by the following mathematical expression:

$$
f=\frac{\Delta y}{\Delta x} \cdot \frac{\partial^{2} \Omega}{\partial v^{2}} .
$$

The sliding mode motion consists of two processes, convergence motion and sliding mode motion, and the sliding mode arrival condition only guarantees the requirement of arriving at the switching surface from the state space point, while no restriction is placed on the convergence motion trajectory. The proposed convergence law can improve the dynamic quality of the convergence motion.

\subsection{Mechanisms of Urban Landscape Design Simulation and} Formation. The extremely large volume of data has also placed demands on the tools used for field collection. The traditional methods of handheld topographic maps, image 
maps, and status maps on paper, using cameras to collect information, and manually viewing the site features are no longer sufficient to meet the current needs of data collection. In the context of big data, mobile GIS, GPS technology, smartphones, and other mobile devices will enter the field research work of the site. Planners can use mobile devices; based on the existing database, the field collection of vector data, photos with location information, action tracks and necessary text descriptions, and other information directly uploaded to the database in the field can be the preliminary planning and design of the site, thus creating a convenient way of research and efficient work methods. Many forms of data are commonly used in landscape planning, such as drawings, text, pictures, dwg files, survey log sheets, verbal notes, and video images. The data currently widely used and available at the planning stage come primarily from the site itself. In addition to the basic information commonly used in planning, such as topographic and geomorphological maps, land use maps, remote sensing image maps, site photos, and multiplanning maps, for specific sites, specific analysis and various targeted surveys are needed, such as soil bearing capacity survey, water quality survey, visitor use survey, vegetation cover survey, and housing quality and use survey. In addition to the abovementioned surveys of the basic information of the site, there are also common data reflecting economic and cultural data, such as the number of visitors, economic revenue, environmental monitoring, video viewing, brochure collection, and basic service facilities. As big data brings more new types of data, such as web text data, communication location data, and social network data, the types of data have increased substantially. The creation of databases is a requirement of the times to promote resource sharing. With the deepening of data openness, more and more data can be obtained through fast, comprehensive, and authoritative official websites, people can freely standardize the use and analysis of data, giving full play to the economic and social value of data and creating a more convenient and comfortable living environment. The database is established as shown in Figure 3.

The current analysis of the site is the basis for the design and reflects the important principle of "respect for the site" in landscape planning and design. The concept of "naturebased" considers people as part of nature. By investigating and analyzing the current situation of the site, we can effectively use the resources of the site, avoid wasting resources, and reflect the culture of the site; we can reasonably plan the spatial functions of the site to meet the needs of users; we can scientifically design the roads and water supply and drainage; we can save the engineering volume and improve the work efficiency. The analysis of the current situation should not be limited to the site; the surrounding resources are also the key point to be examined; the reasonable use of surrounding resources can form a chain reaction of the whole area and drive the development of the region. In a word, the planning and design based on the analysis of the current situation of the site are in line with the actual situation and ecological requirements to meet the scientific, economic, and rational planning and design.
As one of the five elements of design, the terrain embodies the unique skeleton of the site and is the basis of the design. By analyzing the topography of the site, the functional partitioning of the site and the location of attractions can be delineated; for example, plazas and resting points can be set up in flat areas, and vertical activities such as slides and rock climbing can be set up on steep slopes. The study of the topography and geomorphology of the site can effectively reduce the damage to the status quo and also reduce the amount of earthwork; at the same time, it is conducive to the analysis of landscape sightlines and landscape view areas; it is beneficial to the scientific planning of drainage design and elevation analysis, and terrain analysis is the basis of planning and design, which determines the overall style of planning and design. When investigating and analyzing topography and geomorphology, the most important is the elevation and slope analysis, and the traditional terrain analysis is mainly based on field survey by human and site conditions, as the more complex topography of the site cannot be comprehensively investigated and is not conducive to a comprehensive understanding of the site and making analysis and judgment.

As the most representative and attractive street in a city, certain qualities of the physical environment are critical to the urban landscape. One or two of the many elements that make up a streetscape are not enough to create a competent streetscape. Good urban boulevards must meet several basic requirements, including accessibility, the ability to bring people together, public character, livability, safety, comfort, and the potential to encourage residents to participate and take responsibility for the community. All of these qualities can be achieved by design.

\section{Experimental Results and Analysis}

4.1. Results of an Urban Landscape Design Simulation. Vision is undoubtedly the primary way in which people see and feel things. Studies have shown that when people move around on the road, more than $80 \%$ of the information they get about their surroundings comes from vision. In addition to making us aware of the physical form and color of things in the outside world, vision also helps us judge the position and movement of objects, thus allowing us to enjoy beautiful street scenes. On the other hand, since the new century, modern transportation has gradually replaced walking, and most people are moving through the road space at a certain speed. Compared to the low-speed people who traveled and quietly viewed the streetscape, today, most people are in a dynamic situation. An urban landscape design based on a discrete dynamic model driven by big data will be more efficient in landscape design, and its efficiency is shown in Figure 4.

The study of the dynamic visual properties of people is the basis of streetscape design. It can provide several applications in the specific design process. For example, according to the shading relationship between the front landscape and the rear buildings, it can help select street tree species with compound visible height requirements; according to the visual characteristics of people in the plane, 


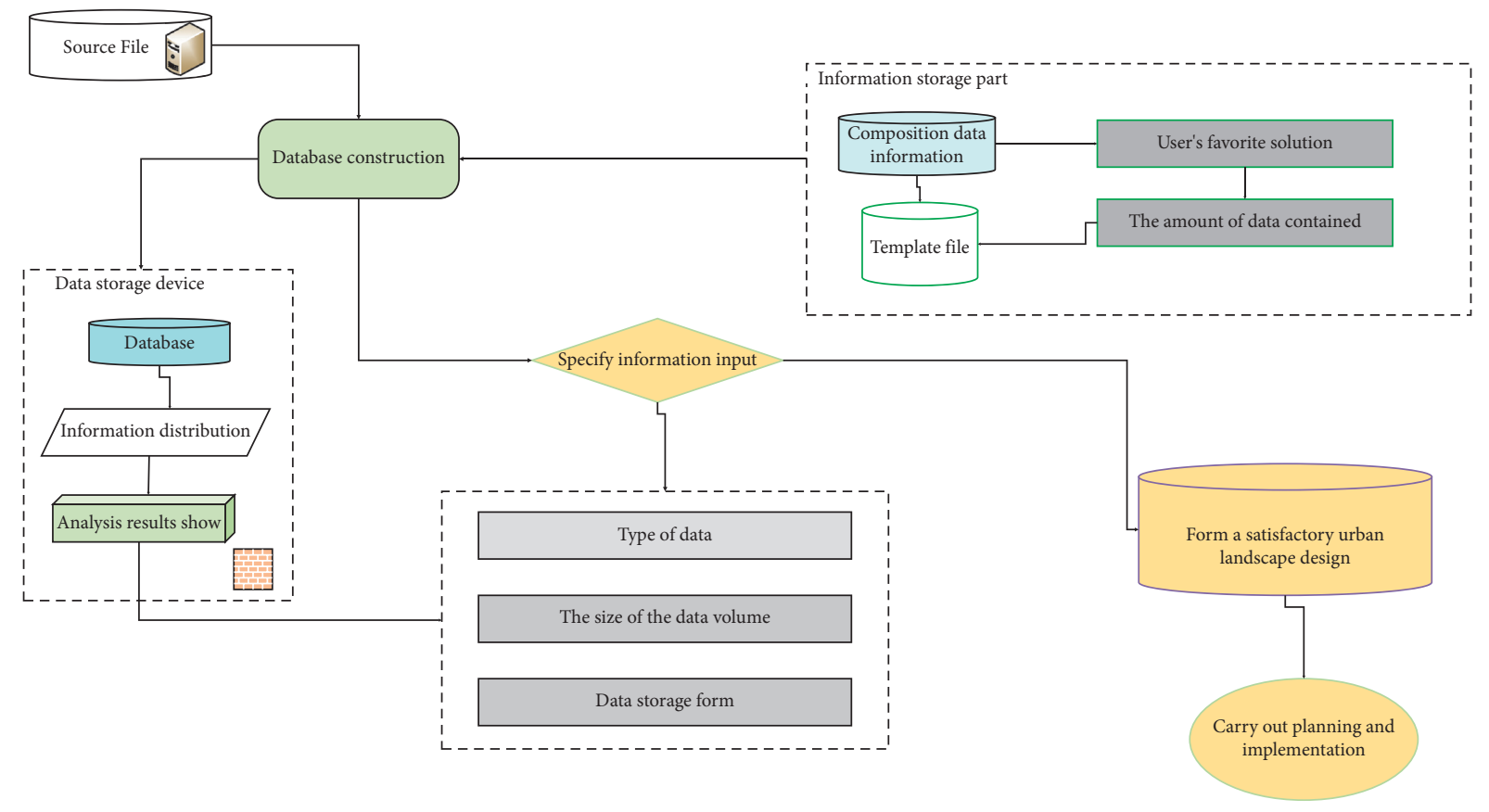

Figure 3: Design diagram of the landscape design database.

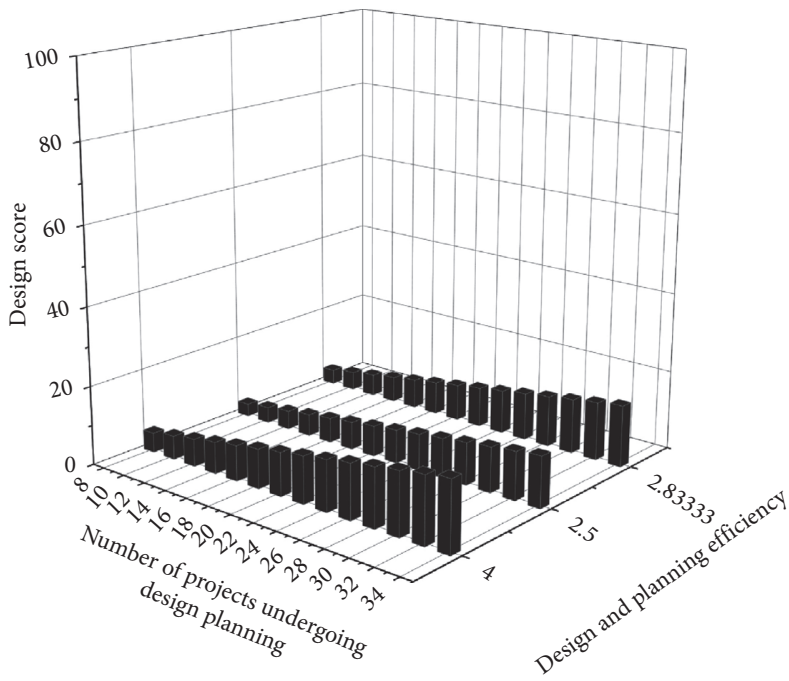

FIgURE 4: The efficiency of discrete dynamic model experiments based on big data.

it can determine the design size of signs or scenery in front of the road; according to the relationship between the speed of vehicles and the recognizable distance of the horizontal landscape of the road, it can determine the appropriate setback distance of buildings on both sides of the road or the width of the roadside landscape zone for different design speeds. According to the relationship between vehicle speed and road longitudinal landscape discernible distance, it can help to determine the scale of green landscape on both sides and the appropriate law of streetscape space change. Therefore, when creating a street landscape environment, matching the changes in the human visual field of view and respecting the dynamic visual characteristics of people can have a multiplier effect and improve the efficiency and quality of the design. The satisfaction level for landscape design with the help of a big data-driven discrete dynamic model of landscape design is shown in Figure 5.

\subsection{Simulation of Urban Landscape Formation Mechanism.} Urbanization is an inevitable law at a certain stage of economic and social development and inevitably brings many problems and contradictions that need to be confronted and faced openly. Moreover, an urban green space design that incorporates an urban agricultural landscape is the solution to the set of problems facing the city that requires a repositioning with the help of the current complex adaptive systems theory. Systems theory of complex adaptation states 


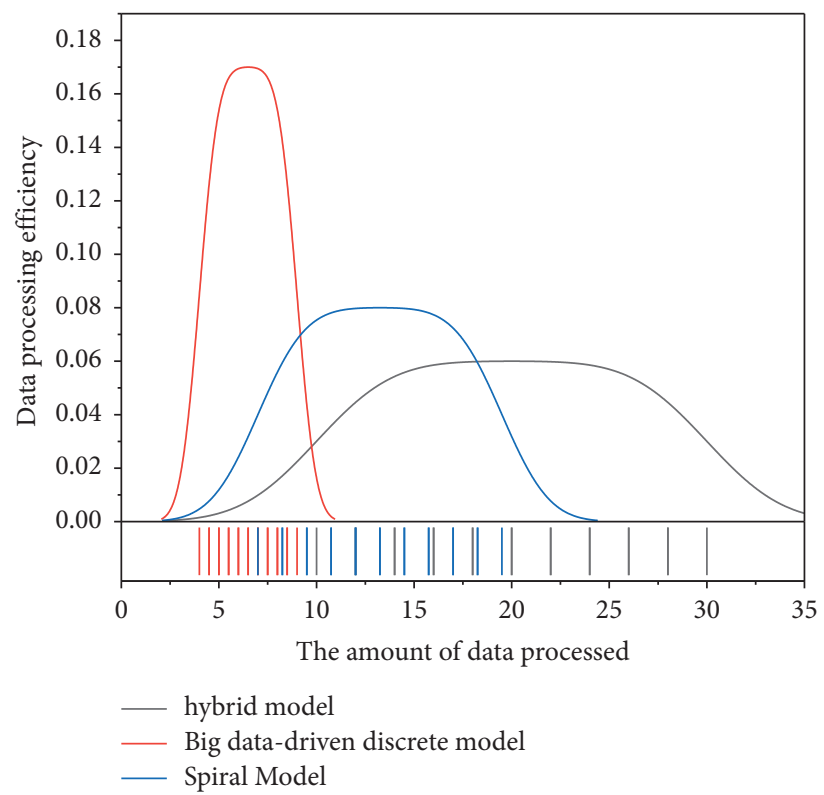

FIgURe 5: Satisfaction with landscape design based on big data-driven discrete dynamic models.

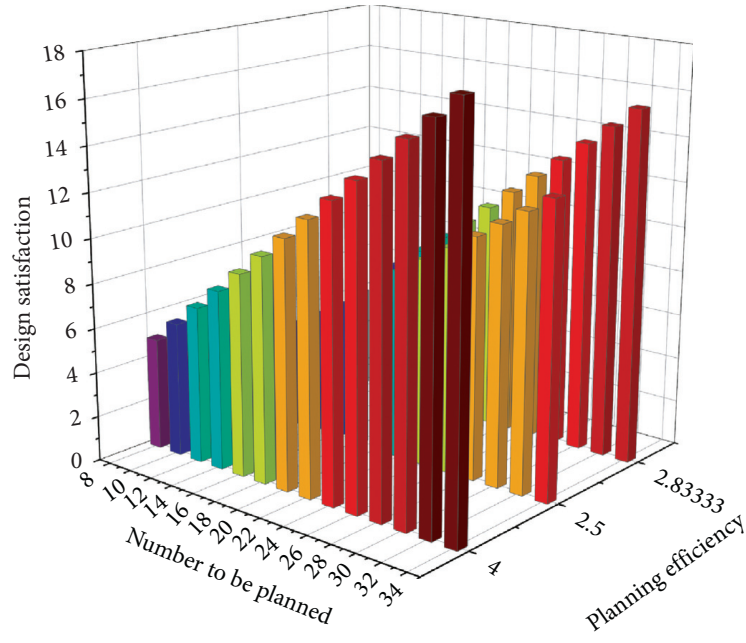

FIGURE 6: Map of the efficiency of the determination of landscaping to engineering based on discrete dynamic models driven by big data.

that the behavior of individuals in adaptive systems of uncertainty leading to an inability to perceive the features to be presented by the system is the dominant factor in the failure of all relevant design projects. Moreover, this potential uncertainty cannot be eliminated. Landscaping based on discrete dynamic models driven by big data can remove its uncertainty even more, with the results shown in Figure 6.

The introduction of urban agricultural landscaping in urban green spaces instead of simply introducing existing ornamental landscaping requires. There are many complex factors to consider, not only in the selection of plants in the design, the creation of the landscape, the composition of the space, and other issues but also in the crop output involved in urban agricultural landscapes, the most typical of which is the planting management of productive agricultural plants, harvesting and distribution issues based on a big data-driven

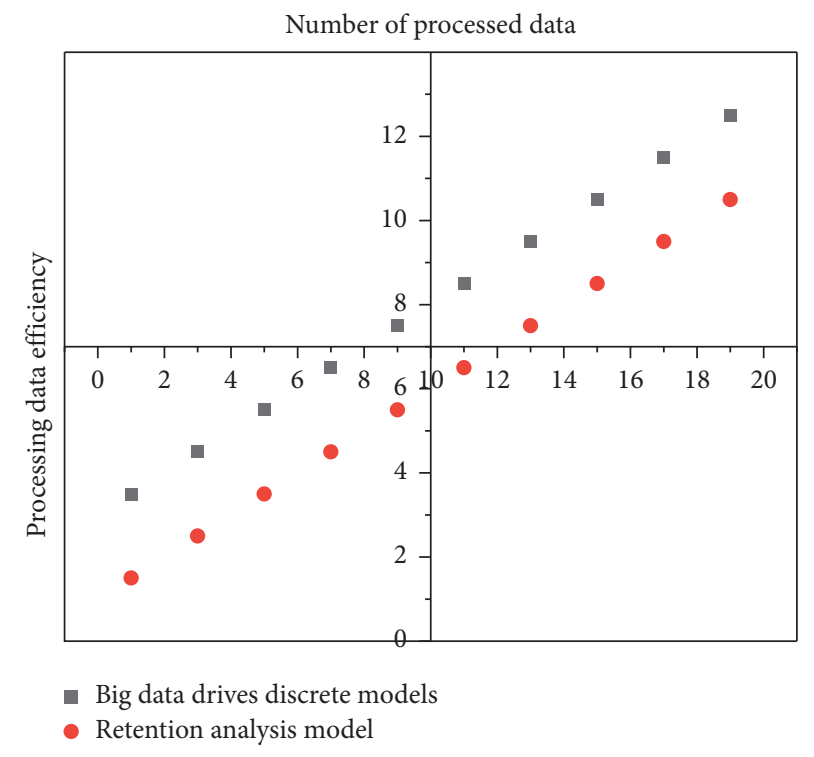

FIGURE 7: Management efficiency of landscape design based on discrete dynamic models driven by big data.

discrete dynamic model of landscape design can solve similar problems of its management. Its efficiency results are shown in Figure 7.

\section{Conclusion}

As a unique type of road, urban landscape avenue must have different functional properties or morphological characteristics from the general road; the current domestic and foreign studies investigate its specific concepts and characteristics, but most of them are still relatively general and one-sided and some are still controversial. The various functional characteristics and spatial morphological requirements of the urban landscape avenue itself make its 
streetscape design very challenging. Some pioneering research and practice have already put forward the streetscape design for the landscape avenue, focused more on the principle, goal, or guide level. However, for the general sense of the road landscape, there are numerous design theories and innovation methods, but few people use them. In this article, through the analysis of the functional characteristics and spatial characteristics of urban landscape boulevards, the integration of classical and innovative theoretical methods of road landscape design, and the introduction of the concept of standardization, we boldly propose a set of streetscape design methods applicable to urban landscape boulevards. This method takes "decomposition-reconstruction" as the core idea, road landscape segmentation as the premise, standard landscape section design as the basis, and the combination of standard sections as the means to finally realize the streetscape design of urban landscape boulevards. In addition, this article uses the method to apply a series of landscape designs based on big data-driven discrete dynamic models in a practical project, and its effect is obvious. This algorithm will be used in the simulation of the city in the future and a series of simulation mechanisms, such as the road planning of the city.

\section{Data Availability}

The data used to support the findings of this study are available from the corresponding author upon request.

\section{Conflicts of Interest}

The authors declare that they have no known conflicts of interest or personal relationships that could have appeared to influence the work reported in this article.

\section{Acknowledgments}

This work was supported by the project of Chongqing Social Science Planning Project, Study on the improvement of service quality and efficiency of recreation space in Chongqing mountainous park during the period of high quality development of space environment, Grant no. 2021NDYB090; National Natural Science Foundation of China, Study on the spatio-temporal differentiation characteristics, environmental resistance, and attraction mechanism of people's recreation behavior in mountain city park based on "context correlation," Grant no. 52108042; Science and Technology Research Program of Chongqing Municipal Education Commission, Research on public service performance evaluation and optimization method of mountain city park, Grant no. KJQN201800824; Natural Science Foundation of Chongqing, Research on crisis situation simulation and spatial governance of mountain parks in Chongqing based on public security, Grant no. cstc2020jcyjmsxmX0329; and Humanities and Social Science Research Projects of Ministry of Education of China, Study on outdoor space and environmental suitability of residential areas based on microbehavior simulation of diverse elderly groups, Grant no. 18YJC760101.

\section{References}

[1] X. Liu, "Three-dimensional visualized urban landscape planning and design based on virtual reality technology," IEEE Access, vol. 8, pp. 149510-149521, 2020.

[2] A. Zhang, W. Li, J. Wu, J. Lin, J. Chu, and C. Xia, "How can the urban landscape affect urban vitality at the street block level? a case study of 15 metropolises in China," Environment and Planning B: Urban Analytics and City Science, vol. 48, no. 5, pp. 1245-1262, 2021.

[3] H. Watkins, J. M. Robinson, M. F. Breed, B. Parker, and P. Weinstein, "Microbiome-inspired green infrastructure: a toolkit for multidisciplinary landscape design," Trends in Biotechnology, vol. 38, no. 12, pp. 1305-1308, 2020.

[4] M. Zhang and X. Deng, "Color effect of landscape architecture design under computer aided collaborative design system," Computer-Aided Design and Applications, vol. 19, no. S3, pp. 13-22, 2021.

[5] Y. Wang, X. Liu, and W. Hu, "The research on landscape restoration design of watercourse in mountainous city based on comprehensive management of water environment," European Journal of Remote Sensing, vol. 54, no. 2, pp. 200210, 2021.

[6] R. Tafahomi, "Qualities of the green landscape in primary schools, deficiencies and opportunities for health of the pupils," Journal of Fundamental and Applied Sciences, vol. 13, no. 2, pp. 1093-1116, 2021.

[7] W. Yuhan, M. Yuxuan, L. Yixuan, and T. Caixin, "Study on ecological structure and landscape optimization of urban landscape plant community based on 3d virtual technology," Design Engineering, vol. 2021, no. 4, pp. 1877-1886, 2021.

[8] T. Z. Cai, "[Phrase omitted]/cultivating the urban wilderness: COLUMN HOST," Landscape Architecture Frontiers, vol. 9, no. 1, pp. 132-134, 2021.

[9] G. A. Aksu and N. Küçük, "Evaluation of urban topographybiotope-population density relations for Istanbul-Beşiktaş urban landscape using AHP," Environment, Development and Sustainability, vol. 22, no. 2, pp. 733-758, 2020.

[10] Y. Ren and S. Guo, "Study on the landscape design strategy of urban old (abandoned) railway--taking the section of Jingmen railway station Wuluju to Shijingshan as an example," International Journal of Social Science and Education Research, vol. 3, no. 8, pp. 286-293, 2020.

[11] J. Bolleter and R. Cameron, "A critical landscape and urban design analysis of Egypt's new administrative capital city," Journal of Landscape Architecture, vol. 16, no. 1, pp. 8-19, 2021.

[12] A. S. Abd Elrahman and M. Asaad, "Urban design \& urban planning: a critical analysis to the theoretical relationship gap," Ain Shams Engineering Journal, vol. 12, no. 1, pp. 1163-1173, 2021.

[13] A. Greasley and J. S. Edwards, "Enhancing discrete-event simulation with big data analytics: a review," Journal of the Operational Research Society, vol. 72, no. 2, pp. 247-267, 2021.

[14] W. Fang, Y. Guo, W. Liao, K. Ramani, and S. Huang, "Big data driven jobs remaining time prediction in discrete manufacturing system: a deep learning-based approach," International Journal of Production Research, vol. 58, no. 9, pp. 2751-2766, 2020.

[15] C. Zhang, Z. Wang, K. Ding, F. T. S. Chan, and W. Ji, “An energy-aware cyber physical system for energy big data analysis and recessive production anomalies detection in discrete manufacturing workshops," International Journal of Production Research, vol. 58, no. 23, pp. 7059-7077, 2020. 
[16] C. Liu, Y. Feng, D. Lin, L. Wu, and M. Guo, "Iot based laundry services: an application of big data analytics, intelligent logistics management, and machine learning techniques," International Journal of Production Research, vol. 58, no. 17, pp. 5113-5131, 2020.

[17] G. H. Popescu, K. Zvarikova, V. Machova, and E. A. Mihai, "Industrial big data, automated production systems, and internet of things sensing networks in cyber-physical systembased manufacturing," Journal of Self-Governance and Management Economics, vol. 8, no. 3, pp. 30-36, 2020.

[18] J. Wen, J. Yang, B. Jiang, H. Song, and H. Wang, "Big data driven marine environment information forecasting: a time series prediction network," IEEE Transactions on Fuzzy Systems, vol. 29, no. 1, pp. 4-18, 2020.

[19] R. Davis, M. Vochozka, J. Vrbka, and O. Neguriţa, "Industrial artificial intelligence, smart connected sensors, and big datadriven decision-making processes in internet of things-based real-time production logistics," Economics, Management and Financial Markets, vol. 15, no. 3, pp. 9-15, 2020.

[20] M. Wiener, C. Saunders, and M. Marabelli, "Big-data business models: a critical literature review and multiperspective research framework," Journal of Information Technology, vol. 35 , no. 1, pp. 66-91, 2020. 